\title{
The $d$-amphetamine-treated Göttingen miniature pig: an animal model for assessing behavioral effects of antipsychotics
}

\author{
F. Josef van der Staay • Bruno Pouzet • Michel Mahieu • \\ Rebecca E. Nordquist • Teun Schuurman
}

Received: 17 January 2009/Accepted: 21 June 2009 / Published online: 23 July 2009

(C) The Author(s) 2009. This article is published with open access at Springerlink.com

\begin{abstract}
Rationale Rodents are usually used to assess the ability of antipsychotic drugs to antagonize hyperlocomotion induced by dopamine agonists, such as the psychostimulant $d$-amphetamine. However, the substantial differences between rodents and humans may hinder extrapolation of experimental results to humans. For this reason, we speculated that Göttingen miniature pigs, which show strong physiological and genetic homology with humans, might be a better model for investigating the effects of antipsychotics. To investigate this, we determined whether $d$-amphetamine induced hyperlocomotion in miniature pigs and whether this effect was reversible by antipsychotics. Materials and methods $d$-Amphetamine was tested in the dose range of 0.2 to $2.0 \mathrm{mg} \mathrm{kg}^{-1}$ for its ability to induce hyperactivity in the open field, and the effects of
\end{abstract}

F. J. van der Staay $\cdot$ T. Schuurman

BioMedical Research,

Wageningen University and Research Center,

Lelystad, The Netherlands

B. Pouzet $\cdot$ M. Mahieu

CNS Discovery Research-Psychiatry, Johnson \& Johnson,

Pharmaceutical Research \& Development,

Beerse, Belgium

F. J. van der Staay $(\bowtie) \cdot$ R. E. Nordquist

Emotion and Cognition Program,

Department of Farm Animal Health, Veterinary Faculty,

Utrecht University,

Yalelaan 7 ,

3584 CL Utrecht, The Netherlands

e-mail: F.J.vanderStaay@UU.NL

F. J. van der Staay $\cdot$ R. E. Nordquist

Rudolf Magnus Institute of Neuroscience, Utrecht University,

Utrecht, The Netherlands two antipsychotics, haloperidol and risperidone, on amphetamine-induced hyperactivity were examined.

Results $d$-Amphetamine increased open-field activity at $0.2,0.4$, and $0.7 \mathrm{mg} \mathrm{kg}^{-1}$ s.c. but not at higher doses. The stimulation of open-field activity induced by $0.4 \mathrm{mg} \mathrm{kg}^{-1}$ s.c. $d$-Amphetamine was antagonized by haloperidol and risperidone ( 0.01 and $0.04 \mathrm{mg} \mathrm{kg}^{-1}$ s.c.).

Conclusion $d$-Amphetamine-induced hyperlocomotion in miniature pigs may be a useful model for studying the effect of putative antipsychotics.

Keywords Locomotor activity - Open field - Amphetamine . Antipsychotic $\cdot$ Haloperidol $\cdot$ Risperidone

\section{Introduction}

Schizophrenia is a debilitating psychiatric disorder that affects about $1 \%$ of the population worldwide (Jablensky et al. 1992). No single treatment alleviates its symptoms, which include psychosis, flattened affect, social withdrawal, and cognitive dysfunction. Although the precise cause of schizophrenia remains unknown, it is established that the dopaminergic system is involved (Björklund and Dunnett 2007; Featherstone et al. 2007; Iversen and Iversen 2007). Indeed, one of the most commonly used methods to screen drugs for antipsychotic-like activity is the ability of a compound to reverse hyperlocomotion caused by dopamine agonists such as amphetamine or apomorphine (Björklund and Dunnett 2007; Higgins 1998; Iversen and Iversen 2007; Weiner et al. 2000). The so-called typical antipsychotics are dopamine $\mathrm{D}_{2}$ receptor antagonists and include drugs such as perphenazine and haloperidol, while atypical antipsychotics act at a number of receptors, including the dopamine $\mathrm{D}_{2}$ receptor and the serotonin $5 \mathrm{HT}_{2 \mathrm{~A}}$ receptor. 
The hyperlocomotion elicited by amphetamine in rats is reversed by both typical and atypical antipsychotics (Geyer and Ellenbroek 2003).

A commonly used rodent model for testing antipsychotic activity is the reversal of dopamine agonist-induced hyperlocomotion. However, while such a model can help elucidate the fundamental mechanisms of disease processes, the phylogenetic distance between rodents and humans makes extrapolation of findings from rats to humans problematic. In contrast, pigs show a strong homology with humans, having a similar physiology, which has led to their use in toxicological research (Svendsen 2006). The pharmacokinetics of a number of drugs, including those administered by the subcutaneous route, are very similar in pigs and humans (Larsen and Rolin 2004). Furthermore, the sequence and chromosome structure of the pig genome shows strong similarity to that of humans (Chen et al. 2007; Lunney 2007; Schook 2007). These similarities mean that pigs could bridge the gap between rodent preclinical research and human clinical studies.

The impracticality of using large animal models in biomedical research (for example, housing, amount of test compound needed, handling) led to the development of the miniature pig (minipig), which is about $25 \%$ the size of a "regular" pig, as laboratory animal (e.g., Chapret et al. 1973; Tumbleson 1986). The advantages of the smaller animal have raised interest in its use as animal model to aid the transition from preclinical to clinical studies (de Groot et al. 2005; Lind et al. 2007; Nunoya et al. 2007; Vodička et al. 2005). Indeed, the minipig, which displays a greater pharmacological similarity to humans than do rodents, is expected to provide a useful animal model for assessing the efficacy and adverse effects of psychoactive agents, such as antipsychotics (e.g., reviewed by Elman et al. 2006; Haddad and Wieck 2004; Jin et al. 2004), and may lead to the identification of side effects not seen in rodent models. This is important because in the past the development of several second-generation antipsychotics was terminated because the drugs had unacceptable side effects in humans (e.g., on the heart and on cholesterol levels), side effects that were not detected during preclinical testing with rodents. Of course, it remains to be established whether such side effects will be seen in minipigs.

Recently, it was shown that $d$-amphetamine evokes dopamine release (Lind et al. 2005a, b) and hyperlocomotion in pigs in an open-field (OF) test (Lind et al. 2005a; Terlouw et al. 1992), similar to the effects of $d$-amphetamine in rodents. This raises the possibility of using pigs to evaluate the antipsychotic-like actions of compounds. The present study was designed to replicate previous findings regarding the behavioral responses of Göttingen minipigs elicited by $d$-amphetamine (Lind et al. 2005a; Terlouw et al. 1992) and to investigate the effect of the typical antipsychotic haloperidol and the atypical antipsychotic risperidone on these responses. A series of four experiments was performed (see Fig. 1) for the following reasons:

1. To determine the lowest dose of $d$-amphetamine that reliably induces behavioral activation in Göttingen minipigs in the $\mathrm{OF}$ test without eliciting overt nonlocomotor effects (experiments 1 and 2)

2. To assess the reproducibility of OF behavior in minipigs

3. To assess the ability of two clinically relevant antipsychotics-haloperidol (experiment 3 ) and risperidone (experiment 4) - to antagonize the $d$ amphetamine-induced behavioral activation

\section{Materials and methods}

Animals

Twenty-four male Göttingen minipigs aged 34-37 weeks (mean 36 weeks) on arrival at our animal facilities were supplied by Ellegaard (Ellegaard Göttingen Miniature pigs ApS, Dalmose, Denmark). All boars were housed individually in two rows of 12 pens, each measuring $80 \times 100 \mathrm{~cm}$. The pens were aligned along a central corridor. The back wall of the pens was made of galvanized steel wire mesh (aperture $7 \mathrm{~cm}$ ). The lower parts of the walls between adjacent pens were made of plastic-coated steel grids to a height of $50 \mathrm{~cm}$; the upper part, to a height of $75 \mathrm{~cm}$, was made of waterproof triplex. The animals could see each other. The front wall consisted of waterproof triplex, measuring 80 (width) $\times 85$ (height) $\mathrm{cm}$ with a door $(60 \mathrm{~cm} \times$ $55 \mathrm{~cm}$ ), above a $20-\mathrm{cm}$ high threshold. All pens were covered with a grating to prevent the pigs from escaping.

Each pen was provided with a food and water dispenser (GROBA Feeding System, Wijchen, The Netherlands). The concrete floor was partially covered with a rubber mat mulched with sawdust as bedding. Environmental enrichment was provided by pieces of wood or chains for biting and chewing and a plastic bucket to play with. The minipigs were kept under a controlled light cycle, lights being on from 0700 to 1900 . All animals were fed approximately $220 \mathrm{~g}$ of chow (ssniff ${ }^{\circledR}$ complete feeds for minipigs, supplier: ssniff, Borchen, Germany), supplemented with a handful of grass pellets (supplier: Waaiboerhoeve, Wageningen University and Research Center, Lelystad, The Netherlands) and half an apple twice daily (approximately at 830 and 1500). Tap water was always available ad libitum. All animals were acclimatized to the facility for 1 week after delivery, after which they were habituated to handling and subcutaneous injections of saline. They were exposed to the OF in 10-min sessions once daily on five successive days. 
Fig. 1 The two phases of the study and the average age (in weeks) of the minipigs at the start of the adaptation period and of the subsequent experiments

\section{Phases and experiments of the study}

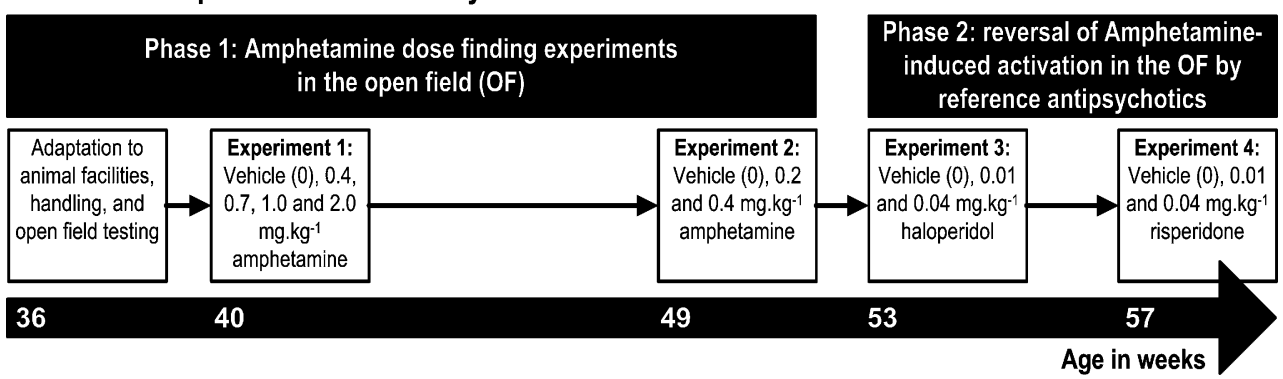

Twenty-four minipigs were assigned to one of three experimental groups, using a random-matched assignment procedure (SAS PLAN Procedure; SAS Institute Inc., Cary, NC, USA) with body mass as matching variable, with the restriction that pigs from the same litter were assigned to different groups (Table 1).

\section{Apparatus}

Two identical OFs, each measuring $230 \mathrm{~cm} \times 340 \mathrm{~cm}$, were used. They were arranged side by side in a room adjacent to the animal vivarium. The side walls were approximately $125 \mathrm{~cm}$ high and made of black waterproof triplex. The right side wall of the right $\mathrm{OF}$ and the back walls of both OFs were placed against the walls of the experimental room. The floor consisted of concrete, covered with black rubber mats. A video camera was mounted in the center above the right side wall of the left $\mathrm{OF}$ and above the left side wall of the right $\mathrm{OF}$, at a height of approximately $2.5 \mathrm{~m}$.

\section{Procedure}

Registration of behavior OF behavior was recorded in 1-h test sessions, using two time-coded Sanyo TLS-9024P A video recorders and analyzed with the video-tracking system EthoVision Color Pro (Version 3.1, Noldus, Wageningen, The Netherlands; Noldus et al. 2001; Spink et al. 2001), using MPEG1-files converted from videotapes recorded with a with Canopus $M P E G^{P R O^{E M R}} E M R 100$ digital video recorder, running MEDIACRUISE application software, or on-line via a Piccolo video-grabber card. Sampling speed was set to 5 frames $\mathrm{s}^{-1}$. In addition, in experiment 1 , the videotaped behavior of the minipigs during the first $2 \mathrm{~min}$ of each of the six successive 10-min blocks of a test session was scored, using an ethogram published by Lind et al. (2005a), extended with the following behaviors: running, jumping, lying, tail wagging, and non-forward locomotion These behaviors and any behavior that was not part of the predefined ethogram were registered using The Observer software (Observer XT, Noldus) by a highly experienced technician. The frequency and duration of these behaviors were recorded.

Test compounds

$d$-Amphetamine was obtained from BUFA b.v. (Uitgeest, The Netherlands) and dissolved in $0.9 \% \mathrm{NaCl}$ solution ( $\mathrm{pH}$ of solution 5.1). Haloperidol and risperidone were obtained from Johnson \& Johnson, Pharmaceutical Research \& Development (Beerse, Belgium). Haloperidol was dissolved in $\mathrm{H}_{2} \mathrm{O}+1 \mathrm{H} 2 \mathrm{~T}$ ( $\mathrm{pH}$ of solution 4), and risperidone was dissolved in $\mathrm{H}_{2} \mathrm{O}+2 \mathrm{H} 2 \mathrm{~T}$ ( $\mathrm{pH}$ of solution 4.08). The solvents of the respective drugs served as vehicle control solutions.

\section{Ethical approval}

The study was reviewed and approved by the local ethics committee (DEC, dierexperimentele commissie) under number 2006177.b and was conducted in accordance with the recommendations of the EU directive 86/609/EEC. All efforts were taken to minimize the number of animals used and their suffering.

Experiment 1: Assessment of the effects of 0.4, 0.7, 1, and $2 \mathrm{mg} \mathrm{kg}^{-1} d$-amphetamine on $\mathrm{OF}$ behavior

Procedure Two pigs (the second heaviest and the second lightest one) were selected from each of the three groups of pigs for the first dose-finding study $(n=6$, see Table 1$)$. The minipigs were then about 40 weeks old. Vehicle $(0.9 \%$ $\mathrm{NaCl}$ solution) or $d$-amphetamine was injected s.c. in a volume of $0.05 \mathrm{ml} \mathrm{kg}^{-1}$ body mass (in the order vehicle, $0.4,0.7$, and $1.0 \mathrm{mg} \mathrm{kg}^{-1} d$-amphetamine, vehicle, $2.0 \mathrm{mg} \mathrm{kg}^{-1} d$-amphetamine), and the $\mathrm{OF}$ session was started directly afterwards. Two minipigs were tested in parallel, i.e., three series of two pigs were tested per day. There was minimally a 3-day washout period between successive test sessions. 
Table 1 Random-matched assignment based on body mass of 24 male minipigs to one of three groups, body mass (kilogram) at 36 weeks of age, and the animals used (and doses administered) in the first and second $d$-amphetamine dose-finding experiments

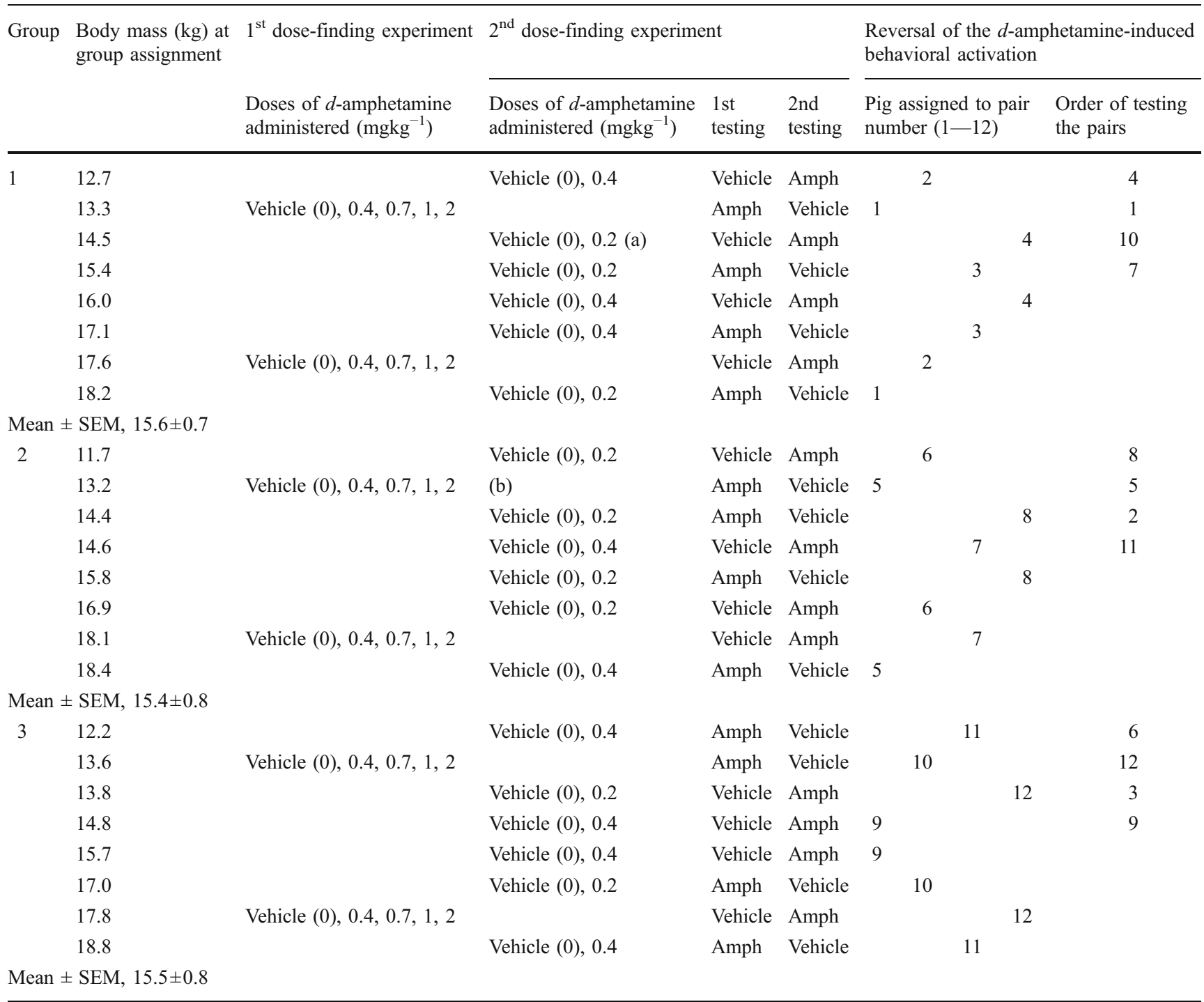

Pigs from the same litter were assigned to different treatment groups. The three groups were randomly assigned to the treatment conditions in the experiments assessing the effects of reference antipsychotics on d-amphetamine-induced behavioral activation in the OF. Within treatment groups, pigs were randomly assigned to pairs. Pigs of a pair were tested in parallel in the two OFs. The order of testing the pairs of pig was randomized and is shown in the last column

Haloperidol experiment-group 1: vehicle of haloperidol; group 2: $0.01 \mathrm{mg} \mathrm{kg}^{-1}$ haloperidol; group 3: $0.04 \mathrm{mg} \mathrm{kg}^{-1}$ haloperidol Risperidone experiment—group 1: $0.01 \mathrm{mg} \mathrm{kg}^{-1}$ risperidone; group 2: $0.04 \mathrm{mg} \mathrm{kg}^{-1}$ risperidone; group 3: vehicle of risperidone

(a) This pig was crippled and had to be replaced by pig (b) [pig received $0.2 \mathrm{mg} \mathrm{kg}^{-1} \mathrm{~d}$-amphetamine; vehicle data are from the second vehicle session of pig (b), obtained in the first dose-finding experiment]

Amph amphetamine

Statistical analysis The behavior of the minipigs in the $\mathrm{OF}$ was analyzed using EthoVision per 20 min intervals. The following parameters were calculated: distance moved (centimeter), mean velocity (centimeter per second), bouts of moving (i.e., frequency of moving), total duration of moving (second), and mean duration of moving per bout (second). The start and stop threshold values used for discriminating movement from immobility with EthoVision were determined from a plot of the velocities (expressed as centimeter per second) per sample $(0.2 \mathrm{~s}$; EthoVision settings: start velocity 30 , stop velocity 10 , no input filter).

The reproducibility of the OF results was assessed by comparing the behavior of the pigs in the two vehicle sessions by a repeated measures analysis of variance (ANOVA) with the factors vehicle sessions (first vs. second) and period (minutes 1-20, 21-40, and 41-60), 
using the SAS GLM procedure. Then, the effects of $d$-amphetamine on behavior in the OF were analyzed statistically with a repeated measures ANOVA (Cotton 1998; Winer 1971) with the within-subject factors dose $(0$, $0.4,0.7,1$, and $2 \mathrm{mg} \mathrm{kg}^{-1} d$-amphetamine) and period (minutes 1-20, 21-40, and 41-60), using the SAS GLM procedure. For this analysis, the second vehicle control session was taken as the drug-free baseline.

Analysis of the three successive 20-min periods (data not shown) revealed that the effects of $d$-amphetamine were most pronounced in the last 20-min period. Therefore, we re-analyzed the video data of the third 20-min period using a within-subjects ANOVA with the repeated measures factor dose $\left(0,0.4,0.7,1\right.$, and $2 \mathrm{mg} \mathrm{kg}^{-1} d$-amphetamine). This analysis was complemented with contrasts. The first series of contrasts was between the doses of $0.4,0.7,1$, and $2 \mathrm{mg} \mathrm{kg}{ }^{-1}$ and vehicle control, in order to determine at which dose(s) of $d$-amphetamine the behavior of the pigs deviated from the baseline (vehicle) measurement. The second series of contrasts compared the successive doses $\left(0-0.4 \mathrm{mg} \mathrm{kg}{ }^{-1} ; 0.4-0.7 \mathrm{mg} \mathrm{kg}^{-1} ; 0.7-1.0 \mathrm{mg} \mathrm{kg}{ }^{-1} ; 1.0\right.$ $2.0 \mathrm{mg} \mathrm{kg}^{-1} d$-amphetamine), in order to determine at which of the increasing dose(s) of $d$-amphetamine OF behavior was affected. The SAS GLM procedure, PROFILE contrasts, was used.

\section{Results}

\section{Reproducibility}

Comparison of the OF behavior in the first and second vehicle sessions confirmed that the OF behavior was highly reproducible (all $F$ values for vehicle sessions and for the periods by vehicle sessions interaction: NS). The activity of the pigs decreased across the three successive observation periods (periods: all $F_{\mathrm{S}_{2}, 10}>5.51, p<0.02$; Fig. 2a-e), indicating intra-session habituation.

\section{Effects of amphetamine}

As mentioned above, the effects of amphetamine on OF behavior were studied in the last 20-min observation period, when vehicle-treated pigs were the least active.

Distance moved (centimeter) $d$-Amphetamine treatment tended to increase the distance moved (dose: $F_{4,20}=2.81$, $0.10>p>0.05$ ). However, contrasts between the vehicle control and increasing doses of $d$-amphetamine confirmed that the $0.4-\mathrm{mg} \mathrm{kg}^{-1}$ dose of amphetamine increased the distance moved, and only tended to increase the distance moved with the two higher doses $\left(0.7\right.$ and $1 \mathrm{mg} \mathrm{kg}^{-1}$ $d$-amphetamine; see Fig. 3a).
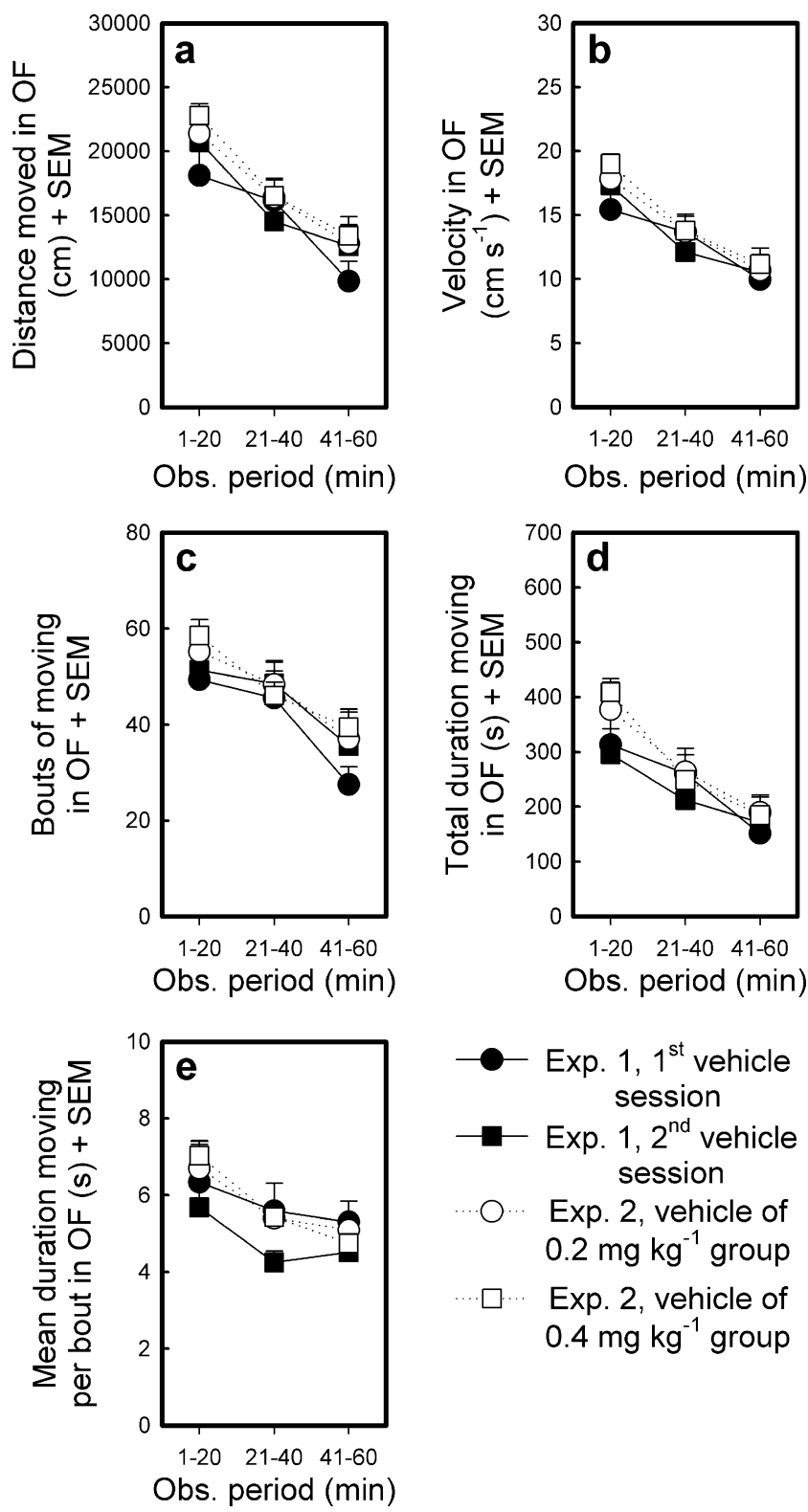

Fig. 2 Reproducibility of the OF data. The OF behavior of minipigs during two vehicle control sessions of experiment 1 (within-subjects design; $n=6$ ) and of two groups of minipigs in the vehicle control session of experiment 2 (between-subjects design; $n=9$ per group) is shown. The distance moved (centimeter; a), mean velocity (centimeter per second; b), bouts of moving (c), total duration of moving (second; d), and mean duration of moving per bout (second; e) are depicted as means and standard errors of the means (SEM) for three successive 20 -min periods. Note that the pigs used in experiment 1 were not used in experiment 2

Mean velocity (centimeter per second) $d$-Amphetamine affected movement velocity (dose: $F_{4},{ }_{20}=3.45$, $p<0.0268$ ) at the doses of 0.4 and $0.7 \mathrm{mg} \mathrm{kg}^{-1}$, as confirmed by analysis of contrasts (see Fig. 3b).

Bouts of moving While ANOVA did not show $d$ amphetamine to increase the number of bouts of moving 

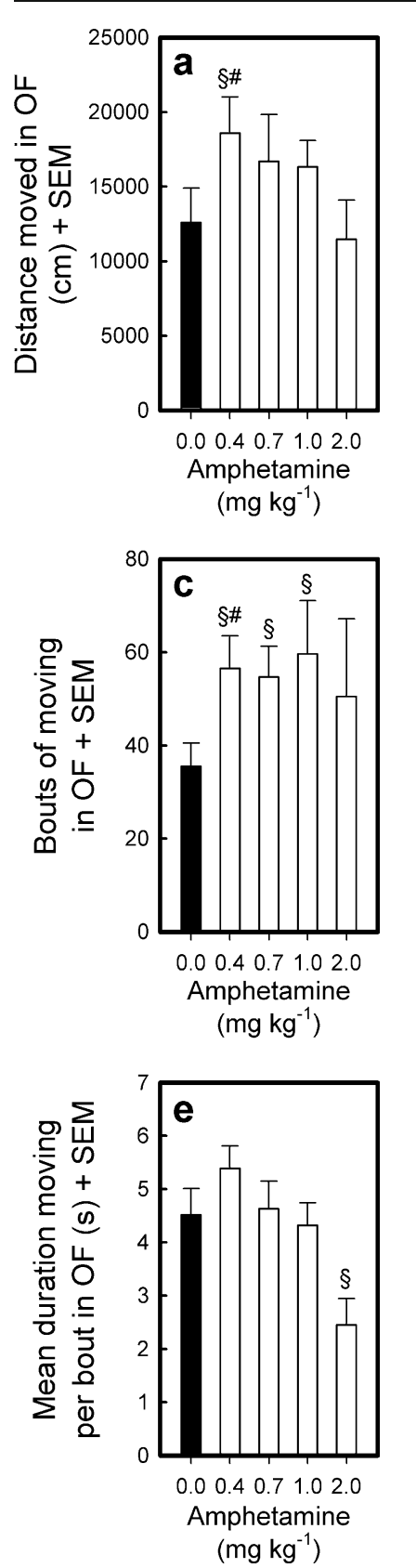

Contrast with vehicle control: $\S: p<0.05$

Contrast with previous dose: \#: $p<0.05$

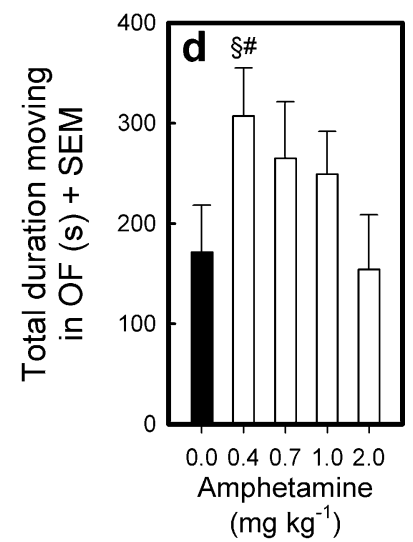

\section{Behavioral observations}

The behavior of the minipigs was scored, using the ethogram published by Lind et al. (2005a), for three treatment conditions: vehicle control and 0.7 (the dose used by Lind et al. 2005a) and $2.0 \mathrm{mg} \mathrm{kg}^{-1} d$-amphetamine ( $t$ statistics on the difference scores between the vehicle and the $d$ amphetamine treatment conditions, i.e., paired comparisons with $d f=5$; see Fig. 4). Only the behaviors that were affected by $d$-amphetamine during at least one of the six 2-min observation periods of a session are shown.

The highest dose of $2 \mathrm{mg} \mathrm{kg}^{-1} d$-amphetamine suppressed measures of OF exploration and activity, whereas $0.7 \mathrm{mg} \mathrm{kg}^{-1} d$-amphetamine increased it (e.g., Fig. 4d), in particular in the second half of the OF session. $d$-Amphetamine did not induce stereotypic behavior. Because direct observation appeared to be relatively insensitive in detecting $d$-amphetamine-induced behavior, automatic video-tracking, with EthoVision, was used in the rest of the experiments.

\section{Experiment 2: Assessment of the effects of 0.2 and $0.4 \mathrm{mg} \mathrm{kg}^{-1} d$-amphetamine on OF behavior}

The effects of $d$-amphetamine found in the previous experiment were generally due to differences between the lowest dose tested and both the highest dose tested and the vehicle control condition. There were no clear effects of $d$ amphetamine according to the ANOVAs performed. The results suggested that the lowest dose tested $\left(0.4 \mathrm{mg} \mathrm{kg}^{-1}\right)$ caused the most pronounced behavioral activation. Because the dose-finding study was based on only six animals, we repeated the experiment with two groups of nine minipigs, using doses of 0.4 and $0.2 \mathrm{mg} \mathrm{kg}^{-1} d$-amphetamine. The 18 drug-naïve pigs from the original batch of 24 animals were used 9 weeks after conclusion of experiment 1 (see Table 1). They were randomly assigned (SAS PLAN procedure) to the treatment orders and $d$-amphetamine doses. The pigs were first assigned to the 0.2 - or $0.4-\mathrm{mg} \mathrm{kg}^{-1} d$-amphetamine treatment and then to one of the two different testing orders 


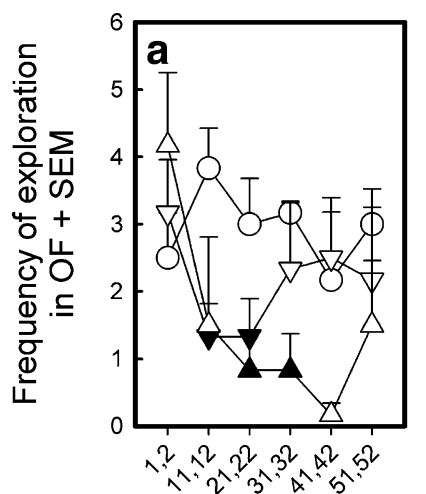

Obs. period ( $\mathrm{min}$ )
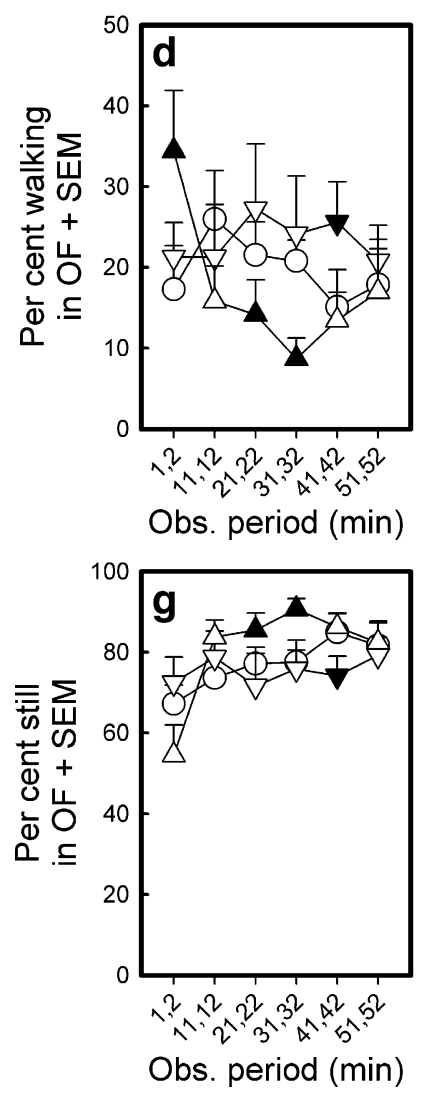

Fig. $4 \mathbf{a}-\mathbf{h}$ Effects of 0.7 and $2 \mathbf{m g ~} \mathbf{k g}^{-\mathbf{1}} d$-amphetamine on $\mathrm{OF}$ behavior of minipigs. Black symbols indicate a difference from vehicle control $(\boldsymbol{p}<0.05$, paired comparison $t$ tests vs. vehicle). The

(vehicle session-washout period- $d$-amphetamine session, or $d$-amphetamine session-washout period-vehicle session). Unfortunately, one of the pigs assigned to the $0.2-\mathrm{mg} \mathrm{kg}^{-1}$ $d$-amphetamine condition was crippled and had to be replaced by a pig that had already been used in the previous dose-finding experiment (see Table 1). The data of the second vehicle session of the first dose-finding experiment for this pig were used as its control values. The OF behavior of all pigs was video-tracked online using EthoVision. Two pigs were tested in parallel.
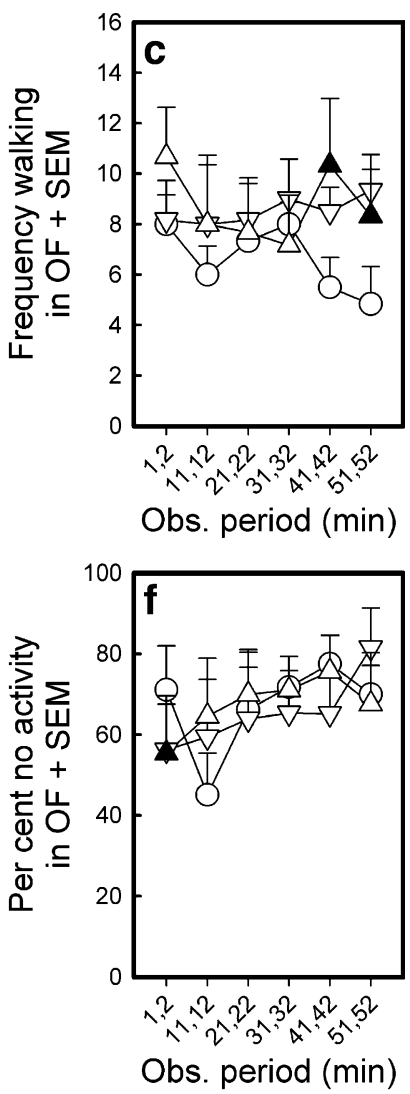

V Vehicle control

$\nabla \quad 0.7 \mathrm{mg} \mathrm{kg}^{-1}$

d-Amphetamine

$\triangle \quad 2.0 \mathrm{mg} \mathrm{kg}^{-1}$

d-Amphetamine

black symbols:

$\mathrm{p}<0.05$

vs. vehicle
Statistical analysis

The data for the two OFs and for the two testing orders were pooled. In order to assess the reproducibility of results, the $\mathrm{OF}$ behavior of the two groups of minipigs during the amphetamine-free sessions was compared by a repeated measures ANOVA (Cotton 1998; Winer 1971) with the factors dose group $\left(0.2,0.4 \mathrm{mg} \mathrm{kg}^{-1} d\right.$-amphetamine) and periods (minutes $1-20,21-40$, and $41-60$ of the $60-\min$ OF test), using the SAS GLM procedure. 
The effect of $d$-amphetamine was most pronounced in the third 20-min OF period (data not shown). Therefore, we analyzed the effects of the two doses of $d$-amphetamine in the last 20-min observation period by an ANOVA with the repeated measures factor session (vehicle vs. $d$-amphetamine session), and the between-subjects factor dose ( 0.2 vs. $0.4 \mathrm{mg} \mathrm{kg}^{-1} d$-amphetamine). The effects of each dose of $d$-amphetamine were, in addition, evaluated by calculating the difference scores between the $d$ amphetamine and the vehicle sessions. The difference scores (delta values) were subjected to one-sample $t$ statistics (with $d f=8$ ).

Results

\section{Reproducibility}

Comparison of the OF behavior of the two groups after administration of vehicle showed the results to be highly reproducible (all $F$ values for the dose group and for the interaction of periods by the dose group $<1.00, \mathrm{NS}$ ). Within sessions, the activity of the pigs decreased across the three observation periods on all measures (periods: all $F_{\mathrm{s}_{2}, 32}>$ $21.50, p<0.0001$; Fig. 2a-e).

\section{Effects of amphetamine}

Distance moved (centimeter) $d$-Amphetamine increased the distance moved (session: $F_{1,16}=24.11, p<0.0002$ ), but there was no difference between the two doses (dose: $F_{1,16}=1.69$, NS; dose by session interaction: $F_{1,16}=1.94$, NS). One-sample $t$ statistics on the difference scores revealed that 0.2 and $0.4 \mathrm{mg} \mathrm{kg} \mathrm{kg}^{-1} d$-amphetamine increased the distance moved (see Fig. 5a).

Mean velocity (centimeter per second) The minipigs moved faster after amphetamine (session: $F_{1},{ }_{16}=23.97, p<$ 0.0002 ), but there was no difference between the two doses (dose: $F_{1,16}=1.69, \mathrm{NS}$, dose by session interaction: $F_{1,16}=$ $1.95, \mathrm{NS})$. One-sample $t$ statistics on the difference scores revealed that the mean velocity in the $\mathrm{OF}$ was increased after treatment with 0.2 and $0.4 \mathrm{mg} \mathrm{kg}^{-1} d$-amphetamine (see Fig. 5b).

Bouts of moving $d$-Amphetamine treatment increased the number of bouts of moving (session: $F_{1,16}=41.11, p<$ 0.0001 ), an effect that appeared to be independent of the dose administered (dose: $F_{1,16}=2.06$, NS; dose by session interaction: $\left.F_{1},{ }_{16}=1.01, \mathrm{NS}\right)$. One-sample $t$ statistics on the difference scores revealed that both doses of $d$-amphetamine treatment increased the number of bouts of moving in the OF (see Fig. 5c).
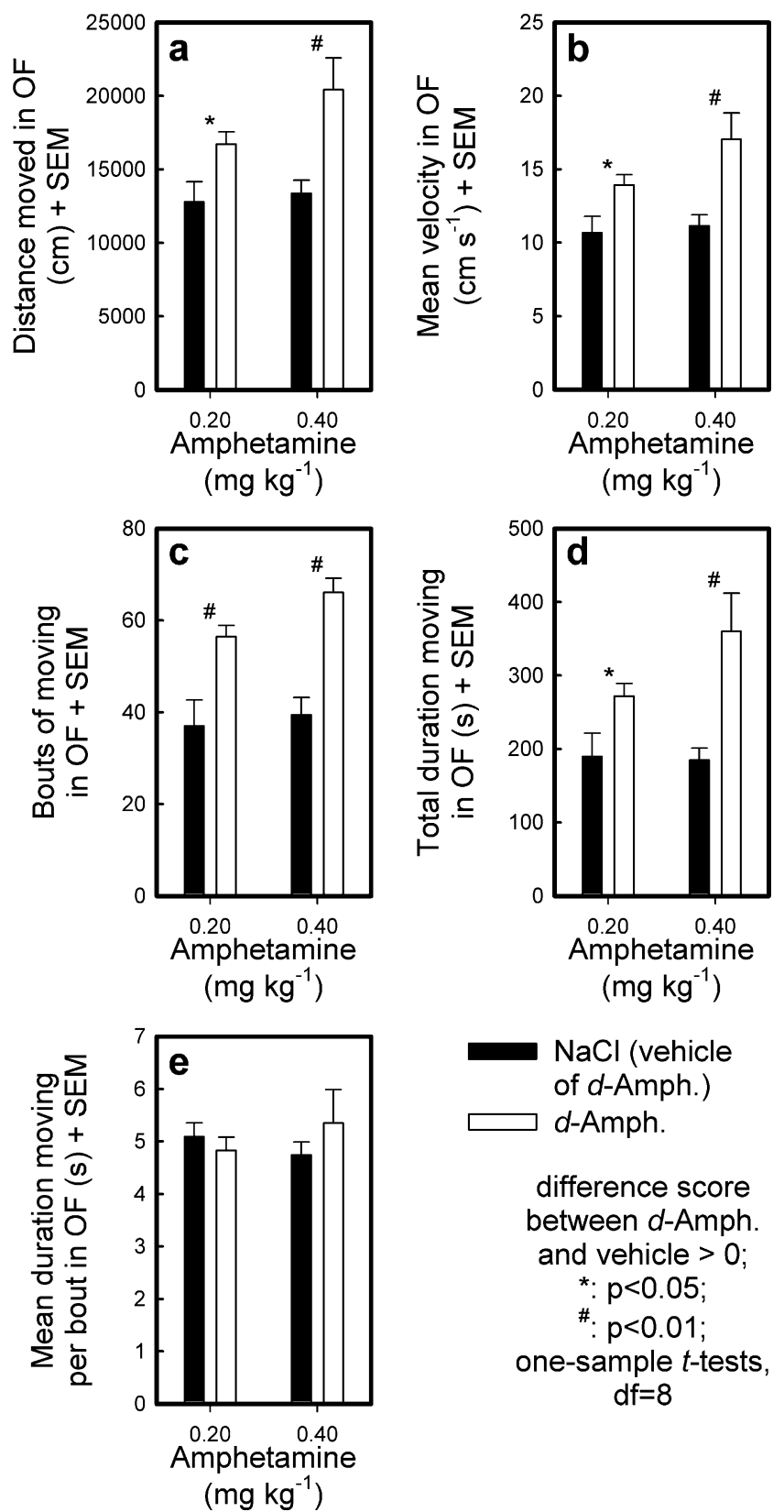

Fig. 5 Effects of 0.2 and $0.4 \mathrm{mg} \mathrm{kg}{ }^{-1} d$-amphetamine on the $\mathrm{OF}$ behavior of minipigs. $d$-Amphetamine or its vehicle was injected s.c., immediately before observations in the OF started. The distance moved (centimeter; a), mean velocity (centimeter per second; b), bouts of moving (c), total duration of moving (second; d), and mean duration of moving per bout (second; e) are depicted as means and standard errors of the means $(S E M)$ of the last 20-min period of the OF test

Total duration of moving (second) Minipigs moved around for longer after amphetamine (session: $F_{1,16}=22.92, p<$ 0.0002 ), but this was not dose-dependent (dose: $F_{1,16}=$ 1.24 , NS, dose by session interaction: $F_{1,16}=3.02$, NS). One-sample $t$ statistics on the difference scores revealed 
that the time spent moving increased after 0.2 and $0.4 \mathrm{mg} \mathrm{kg}^{-1} d$-amphetamine (see Fig. $5 \mathrm{~d}$ ).

Mean duration of moving per bout (second) The mean duration of moving per bout was unaffected by $d$ amphetamine treatment (session: $F_{1,16}=0.27$, NS; dose: $F_{1,16}=0.04$, NS; session by dose interaction: $F_{1,16}=1.69$, NS; see Fig. 5e).

In summary, the minipigs appeared to have a stable pattern of behavior in the OF, alternating between standing still and short, forward movements. While the duration of these bouts of moving was unaffected by either dose of $d$-amphetamine, the distance moved, the velocity of moving, the bouts of moving, and the total duration of moving in the OF were increased by both doses of $d$-amphetamine. Because the absolute effect size appeared to be larger for $0.4 \mathrm{mg} \mathrm{kg}^{-1} d$-amphetamine, the remaining two experiments were performed with this dose.

\section{Experiments 3 and 4: Reversal of $d$-amphetamine-induced behavioral activation in the OF by the antipsychotic compounds haloperidol and risperidone}

The ability of the antipsychotic compounds haloperidol and risperidone to antagonize the $d$-amphetamine $\left(0.4 \mathrm{mg} \mathrm{kg}^{-1}\right)$ induced behavioral activation in the OF was tested. Three groups of eight minipigs (one vehicle and two dose groups) were tested twice, once after injection of the $d$-amphetamine vehicle and once after injection of $0.4 \mathrm{mg} \mathrm{kg}^{-1} d$ amphetamine. The minipigs were assigned to groups on the basis of body mass when they were about 36 weeks old (see Table 1), and then, they were randomly assigned per group to one of four pairs. The treatment order was randomly determined per pair of pigs (first testing/second testing), and the order of testing of the pairs was determined by random permutation of the three treatment groups. All randomizations were performed using the SAS PLAN procedure. An animal was never tested more than twice a week. The inter-test session interval, i.e., washout period, was never less than 3 days. Videotaping and analysis of $\mathrm{OF}$ behavior was performed as described above.

Statistical analysis The data of the third 20-min OF period were analyzed using a two-factorial repeated measures ANOVA (Cotton 1998; Winer 1971) with dose (vehicle, low dose, high dose) of the antipsychotic drugs (haloperidol, risperidone) as between-subjects factor and $d$-amphetamine (vehicle, $0.4 \mathrm{mg} \mathrm{kg}^{-1} d$-amphetamine) as within-subjects factor. In addition, the effects of the two doses of the antipsychotics on the effects of $d$-amphetamine were assessed by an ANOVA on the difference (delta) between the $d$-amphetamine session and the $d$-amphetamine vehicle session, followed by Fisher's least significant difference (LSD) pairwise comparisons between the three groups treated with different doses of the antipsychotic drug. The delta values are indices of the size of the effect of $d$-amphetamine.

The effects of haloperidol and risperidone on the OF behavior of the minipigs were assessed in an ANOVA with the factor dose; this analysis was based on the data from the $d$-amphetamine vehicle sessions. The analyses were supplemented with Fisher's post hoc LSD comparisons between dose groups, where appropriate.

\section{Experiment 3: Results (haloperidol)}

Distance moved (centimeter) $d$-Amphetamine tended to increase the distance moved in the OF $\left(F_{1,21}=4.30, p<\right.$ $0.0506)$. Haloperidol decreased the distance moved $\left(F_{2,21}=\right.$ $8.56, p<0.0019)$, a finding that was confirmed by analysis of the $d$-amphetamine-free sessions (haloperidol: $F_{2,2}=5.38$, $p<0.0139)$. The ANOVA failed to detect an interaction between the effects of the two compounds ( $d$-amphetamine by haloperidol interaction: $F_{2},{ }_{21}=2.10$, NS). However, because visual inspection of Fig. 6a suggested that haloperidol dose-dependently antagonized the $d$-amphetamineinduced increase of distance moved in the OF, we performed a post hoc analysis. This analysis revealed that the high dose of haloperidol strongly decreased the distance moved compared with the vehicle control group, whereas the distance moved of the group treated with the low dose of haloperidol was intermediate between the vehicle group and the group treated with the high dose and did not differ from either.

Mean velocity (centimeter per second) Treatment with $d$-amphetamine tended to increase the mean velocity $\left(F_{1,21}=4.14,0.10>p>0.05\right)$. Haloperidol decreased the mean velocity dose dependently $\left(F_{2,21}=8.54, p<0.0019\right)$. This effect was confirmed in a separate ANOVA of the $d$-amphetamine-free sessions (haloperidol: $F_{2}, 21=5.04$, $p<0.0163)$. There was no interaction between the effects of the $d$-amphetamine and haloperidol $\left(F_{2,21}=2.13, \mathrm{NS}\right)$. However, post hoc comparisons confirmed the impression that the group of minipigs treated with the high dose of haloperidol $\left(0.04 \mathrm{mg} \mathrm{kg}^{-1}\right)$ moved around slower than the vehicle-treated group, whereas the group treated with the low dose $\left(0.01 \mathrm{mg} \mathrm{kg}^{-1}\right)$ moved at a speed intermediate between that of the vehicle group and the high-dose haloperidol group, and did not differ from both (see Fig. 6b). 

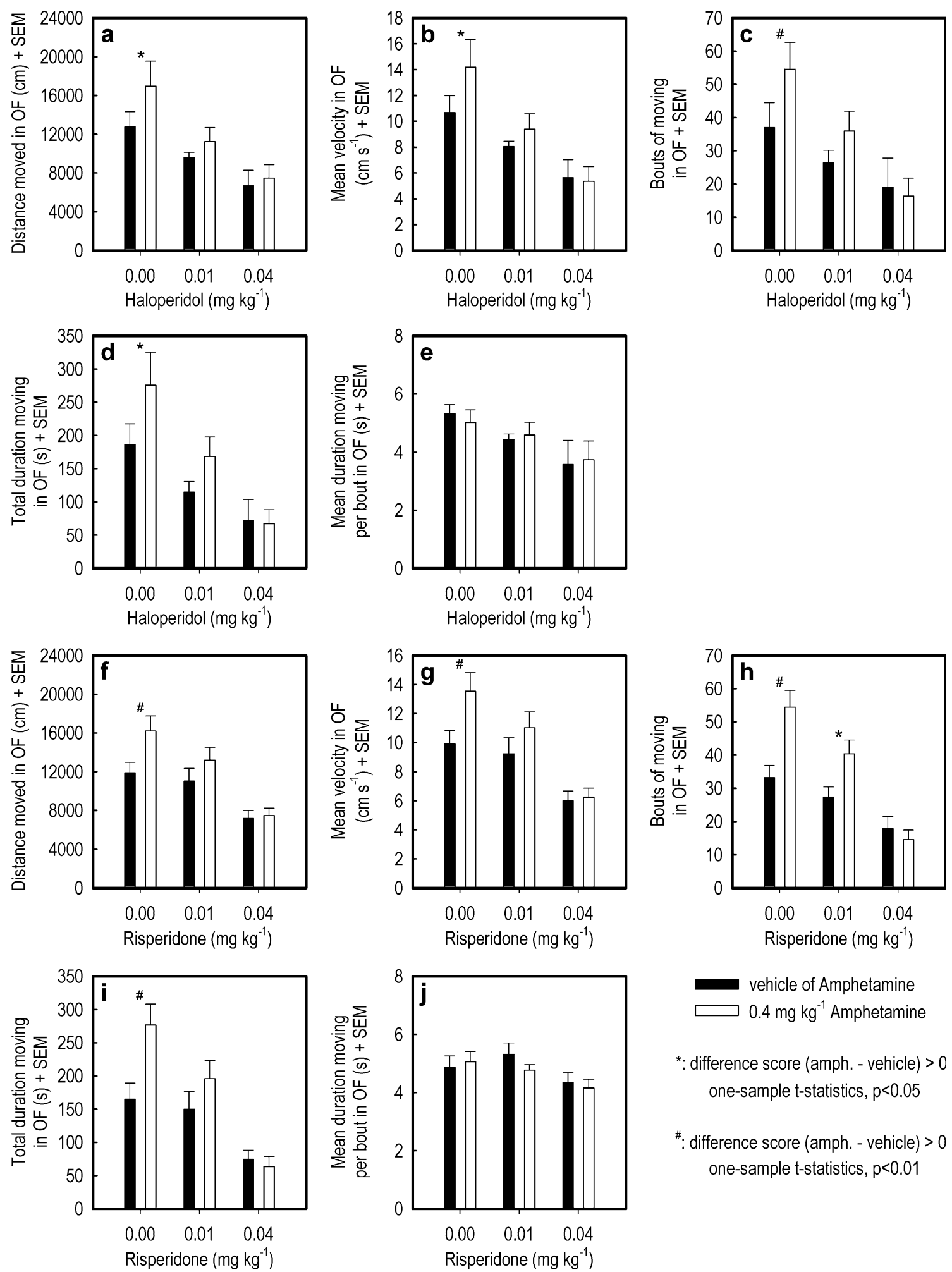

*: difference score (amph. - vehicle) $>0$

one-sample t-statistics, $p<0.05$

\#: difference score (amph. - vehicle) $>0$

one-sample t-statistics, $p<0.01$

Fig. 6 Effects of $0.4 \mathrm{mg} \mathrm{kg}{ }^{-1} d$-amphetamine and the reference antipsychotics haloperidol $\left(0.01\right.$ or $0.04 \mathrm{mg} \mathrm{kg}^{-1}$; first and second rows, a-e) and risperidone ( 0.01 or $0.04 \mathrm{mg} \mathrm{kg}^{-1}$; third and fourth rows, $\mathbf{f}-\mathbf{j}$ ) on the $\mathrm{OF}$ behavior of minipigs. $d$-Amphetamine or its vehicle was injected s.c., immediately before observations in the $\mathrm{OF}$ started. The reference antipsychotic or its vehicle was injected s.c.

approximately $30 \mathrm{~min}$ before the minipigs were tested in the OF. For each of the two reference antipsychotics, the distance moved (centimeter), mean velocity (centimeter per second), bouts of moving, total duration of moving (second), and mean duration of moving per bout (second) are depicted as means and standard errors of the means (SEM) of the last 20-min period of the OF test 
Bouts of moving $d$-Amphetamine increased the number of bouts of moving $\left(F_{1,21}=5.37, p<0.0307\right)$. Haloperidol decreased this measure $\left(F_{2,21}=5.39, p<0.0129\right)$, as confirmed by analysis of the $d$-amphetamine-free sessions. Haloperidol tended to affect the $d$-amphetamine-induced increase of the number of bouts of moving differentially ( $d$-amphetamine by haloperidol interaction: $F_{2,21}=2.76$, $0.10>p>0.05)$. However, separate ANOVA on the $d$ amphetamine-free sessions did not confirm this finding (haloperidol: $F_{2,21}=1.65$, NS), and subsequent post hoc comparisons did not detect differences between the different doses of haloperidol (see Fig. 6c).

Total duration of moving (second) $d$-Amphetamine treatment increased the total duration of moving $\left(F_{1,21}=7.10\right.$, $p<0.0145$ ), whereas haloperidol decreased this measure $\left(F_{2,21}=8.68, p<0.0018\right)$. The haloperidol effect was also confirmed in the separate analysis that was restricted to the $d$-amphetamine-free sessions (haloperidol: $F_{2,21}=4.62, p<$ 0.0217). Haloperidol did not differentially affect the $d$-amphetamine-induced increase of the total duration of moving ( $d$-amphetamine by haloperidol interaction: $F_{2,21}=$ 2.47, NS). Visual inspection of Fig. $6 \mathrm{~d}$ suggested that haloperidol antagonized the $d$-amphetamine-induced increase in total duration of moving dose dependently. This impression was supported by post hoc comparisons: treatment with $0.04 \mathrm{mg} \mathrm{kg}^{-1}$ haloperidol decreased the total duration of moving compared with the vehicle-treated group. The group treated with $0.01 \mathrm{mg} \mathrm{kg}^{-1}$ haloperidol spent time moving in the $\mathrm{OF}$ intermediate between the vehicle group and the high-dose group. The low dose group did not differ from the two other groups on this measure (see Fig. 6d).

Mean duration ambulating per bout (second) $d$-Amphetamine did not affect the mean duration ambulating per bout $\left(F_{1,21}=0.00, \mathrm{NS}\right)$. Haloperidol treatment caused a decrease of this measure $\left(F_{2,21}=6.53, p<0.0063\right)$. This result was only weakly confirmed by analysis of the $d$-amphetaminefree sessions (haloperidol: $F_{2,21}=2.86,0.10>p>0.05$ ). There was no interaction between the effects of $d$ amphetamine and haloperidol $\left(F_{2,21}=0.11\right.$, NS; see Fig. 6e)

\section{Experiment 4: Results (risperidone)}

Distance moved (centimeter) $d$-Amphetamine increased the distance moved in the OF $\left(F_{1,21}=9.69, p<0.0053\right)$. Risperidone decreased the distance moved $\left(F_{2,21}=12.32\right.$, $p<0.0003$ ), a finding that was confirmed by analysis of the $d$-amphetamine-free sessions (risperidone: $F_{2,21}=5.37, p<$ $0.0131)$. Although there was no interaction between the effects of $d$-amphetamine and risperidone $\left(F_{2,21}=2.10\right.$,
NS), visual inspection of Fig. 6f suggested that risperidone dose dependently antagonized the effects of $d$-amphetamine on the distance moved. Post hoc analysis confirmed that the high dose of risperidone strongly decreased the distance moved compared with the vehicle control group, and the group treated with the low dose of risperidone, which did not differ from one another (see Fig. 6f).

Mean velocity (centimeter per second) Treatment with $d$-amphetamine increased the mean velocity $\left(F_{1,21}=9.75\right.$, $p<0.0051)$. Risperidone decreased the mean velocity $\left(F_{2,21}=\right.$ $12.44, p<0.0003)$. This effect was confirmed in a separate ANOVA on the $d$-amphetamine vehicle sessions (risperidone: $F_{2,21}=5.25, p<0.0138$ ). Treatment with risperidone tended to affect the effects of $d$-amphetamine differentially ( $d$-amphetamine by risperidone interaction: $F_{2,21}=2.60$, $0.10>p>0.05)$. Post hoc comparisons confirmed that the group of minipigs treated with the high dose of risperidone $\left(0.04 \mathrm{mg} \mathrm{kg}^{-1}\right)$ moved around in the OF with a lower speed than the vehicle-treated group and the group treated with the low dose of risperidone $\left(0.01 \mathrm{mg} \mathrm{kg}^{-1}\right)$. The latter two groups did not differ from one another (see Fig. 6g).

Bouts of moving The number of bouts of moving increased after $d$-amphetamine treatment $\left(F_{1,21}=23.74, p<0.0001\right)$, whereas risperidone decreased this measure $\left(F_{2,21}=17.90\right.$, $p<0.0001)$. Separate ANOVA on the $d$-amphetamine vehicle sessions confirmed this finding (risperidone: $F_{2,21}=$ 5.07, $p<0.0160$ ). Risperidone dose dependently antagonized the $d$-amphetamine-induced increase of the number of bouts of moving ( $d$-amphetamine by risperidone interaction: $F_{2,21}=$ $11.53, p<0.0004)$. Subsequent post hoc comparisons revealed that the high dose of risperidone decreased the number of bouts of moving compared with the control condition. In the group treated with the low dose of risperidone, the number of bouts was intermediate between that of the two other groups (see Fig. 6h).

Total duration of moving (second) d-Amphetamine treatment increased the total duration of moving $\left(F_{1,21}=\right.$ $10.03, p<0.0046)$, whereas risperidone decreased the total duration of moving $\left(F_{2,21}=15.28, p<0.0001\right)$. This effect of risperidone was also confirmed in the separate ANOVA that was restricted to the $d$-amphetamine-free sessions (risperidone: $F_{2,21}=4.72, p<0.0203$ ). Risperidone dose dependently antagonized the $d$-amphetamine-induced increase in total duration of moving $(d$-amphetamine by risperidone interaction: $\left.F_{2,21}=5.25, p<0.0140\right)$. Post hoc comparisons confirmed that treatment with $0.04 \mathrm{mg} \mathrm{kg}^{-1}$ risperidone decreased the total duration of moving compared with the vehicle-treated group and the group treated with $0.01 \mathrm{mg} \mathrm{kg}^{-1}$ risperidone; these two groups did not differ from one another (see Fig. 6i). 
Mean duration of moving per bout (second) Neither $d$-amphetamine $\left(F_{1,21}=0.76, \mathrm{NS}\right)$ nor risperidone $\left(F_{2,21}=\right.$ 2.51 , NS) affected the mean duration ambulating per bout. The lack of effect of risperidone was confirmed by analysis of the $d$-amphetamine vehicle sessions (risperidone: $F_{2}, 21=1.72$, NS). There was no interaction between the effects of $d$-amphetamine and risperidone $(d$ amphetamine by risperidone interaction: $F_{2,21}=1.05$, NS; see Fig. 6j).

Body mass Analysis of variance with the factor group (groups 1 to 3; see Table 1) and the repeated measures factor age $(36,49,53,64,68$, and 72 weeks of age) showed that the groups of minipigs were of similar body mass (36-weekold: $F_{2,}{ }_{21}=0.02, \mathrm{NS} ; 49$-week-old: $F_{2,21}=0.69$, NS; 53-week-old: $F_{2,21}=0.83, \mathrm{NS}$; 64-week-old: $F_{2,21}=1.25$, NS; 68-week-old: $F_{2,21}=0.74,72$-week-old: $F_{2,21}=0.49$, NS; general mean, i.e., average across all time points: $F_{2,21}=0.61, \mathrm{NS}$ ), and that the three groups gained weight at a similar rate (age: $F_{5}, 105=753.27, p<0.0001$; group by age interaction: $F_{10,105}=0.91$; NS; see Fig. 7 ).

\section{Discussion}

Pigs have a highly developed central nervous system and their physiology, pharmacokinetics, and genetics are similar to those of humans (Larsen and Rolin 2004). Given these similarities, we expected that minipigs would be a useful model that closes the gap between preclinical drug testing in rodents and clinical testing in humans (de Groot et al. 2005; Lind et al. 2007; Nunoya et al. 2007; Vodička et al. 2005). We investigated whether the $d$-amphetamine-treated pig could serve as an animal model for testing the antipsychotic-like actions of compounds. To this end, we first determined the lowest dose of $d$-amphetamine

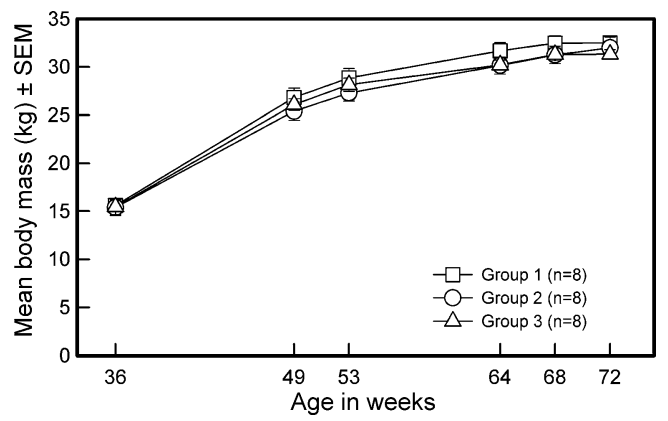

Fig. 7 Average body mass (kilogram) and standard error of the mean $(S E M)$ of minipigs that were allocated to three different treatment groups by random matched assignment, based on their weights at the age of 36 weeks. The composition of the three groups is shown in Table 1. Note that the stable increase in body mass in the three groups of minipigs continued beyond the age at which the last experiment of the present study was performed $\left(0.4 \mathrm{mg} \mathrm{kg}^{-1}\right)$ that reliably induced activation in the $\mathrm{OF}$ without inducing obvious side effects and used this dose to determine whether the antipsychotics haloperidol and risperidone could antagonize the $d$-amphetamine-induced OF activation.

\section{Reproducibility of open-field behavior in minipigs}

Analyses assessing the reproducibility of the OF behavior of the minipigs, using both a within-subjects design and a between-subjects design, showed that the OF behavior of the minipigs was highly reproducible when tested after administration of the vehicle.

\section{Methodological considerations}

Group size Although six Göttingen minipigs per group were used in the first dose-finding study, results were more robust when nine minipigs were used per group in the second dose-finding study. Larger groups may increase the sensitivity to detect interactions between the effects of $d$-amphetamine and of clinically applied or putative novel antipsychotics.

Direct observations based on the extended Lind ethogram We found that assessment of the effects of $d$-amphetamine on OF behavior by direct observation, using a published ethogram (Lind et al. 2005a), was time- and resource-consuming and rather insensitive to detect $d$-amphetamine-induced changes in OF behavior. In contrast, the video-tracking method was sensitive enough to reproducibly detect the effects of low doses of $d$-amphetamine. Our findings confirm and extend the observations of Lind and colleagues, who investigated the effects of $0.7 \mathrm{mg} \mathrm{kg}^{-1} d$-amphetamine on the $\mathrm{OF}$ behavior of Göttingen minipigs (Lind et al. 2005a).

Habituation of vehicle groups Despite extensive habituation to the test setup in the days preceding testing, a strong within-session habituation effect was detected in the vehicle-treated groups, with decreasing activity seen over the three successive 20-min periods (see Fig. 2). This decrease in activity in the vehicle group increased the difference between $d$-amphetamine- and vehicle-treated groups. Longer habituation times on the test day itself, prior to injection may help to improve future experiments.

\section{$d$-Amphetamine dose-finding experiments}

The effects of $d$-amphetamine on the OF behavior of Göttingen minipigs were assessed in two experiments. The maximal increase in OF behavior was $50 \%$, elicited with $0.4 \mathrm{mg} \mathrm{kg}^{-1}$ amphetamine. A lower, but not higher, dose also 
affected the pigs' OF behavior, but the absolute effect sizes were smaller than those found with $0.4 \mathrm{mg} \mathrm{kg} \mathrm{kg}^{-1}$ $d$-amphetamine, and they emerged later during the 1-h OF sessions (data not shown). It is worth noting that the $50 \%$ maximum increase in OF behavior is much smaller than that elicited by $d$-amphetamine in rats (nearly $2,000 \%$; Nordquist et al. 2008b) and mice (350\%; Nordquist et al. 2008a). The dose-response curve may be shifted to the right in rodents, and the effective dose range in rats appears to be wider than that observed in minipigs (Grilly and Loveland 2001). Interestingly, the dose of $0.4 \mathrm{mg} \mathrm{kg}^{-1}$ is also identical to that shown to induce restlessness in non-human primates (Peacock and Gerlach 1999; Peacock et al. 1999). The few studies that have reported on amphetamine-induced locomotion in humans have reported very little effect or decreased, rather than increased, locomotion (Grilly and Loveland 2001). We found a decrease at the highest dose tested ( $2 \mathrm{mg} \mathrm{kg}^{-1}$ body mass), which could suggest that high doses cause motor side effects. Psychostimulant-induced locomotion is considered a model of psychostimulant-induced psychosis in humans. In a study of patients who had experienced a single psychotic episode, a single dose of $18 \mathrm{mg}$ of amphetamine increased scores on the Brief Psychotic Rating Scale. Assuming an average weight of $70 \mathrm{~kg}$, this translates to $0.26 \mathrm{mg} \mathrm{kg}^{-1}$. Our results may indicate that the relatively modest increase in locomotion induced by amphetamine in minipigs better reflects the effects of amphetamines on human and non-human primate behavior than the large increase in locomotion elicited by amphetamine in rodents.

Effects of the antipsychotic compounds haloperidol and risperidone on $\mathrm{OF}$ behavior

We found that both haloperidol $\left(0.04 \mathrm{mg} \mathrm{kg}^{-1}\right)$ and risperidone $\left(0.04 \mathrm{mg} \mathrm{kg}^{-1}\right)$ decreased spontaneous locomotor activity (distance moved, mean velocity, and total duration of moving). Lind et al. also reported a decrease in OF activity in pigs after administration of $0.2 \mathrm{mg} \mathrm{kg}^{-1}$ haloperidol (Lind et al. 2005a). By comparison, haloperidol decreased activity in rats at $0.08 \mathrm{mg} \mathrm{kg}^{-1}$ s.c., but not at $0.04 \mathrm{mg} \mathrm{kg}^{-1}$ s.c., and risperidone decreased spontaneous locomotion at $0.62 \mathrm{mg} \mathrm{kg}^{-1}$ s.c., but not at $0.18 \mathrm{mg} \mathrm{kg}^{-1} \mathrm{~s}$. c. (Bardin et al. 2007). Thus, the doses of haloperidol and risperidone that inhibited spontaneous locomotion were lower in minipigs than in rodents. This may indicate that minipigs are more sensitive to antipsychotics, but this needs to be substantiated in pharmacokinetic studies. One of the few studies to examine the effects of acute dosing of antipsychotics on locomotion in healthy humans demonstrated a lack of effect of haloperidol at a dose of $2 \mathrm{mg}$ p.o., the only dose tested (Kiang et al. 2003). The weight of the subjects was not reported, but assuming an average weight of
$70 \mathrm{~kg}$, a single dose of $2 \mathrm{mg}$ p.o. translates to $0.03 \mathrm{mg} \mathrm{kg}{ }^{-1}$ p.o., a dose that would not be expected to produce locomotor suppression on the basis of pig or rat data. However, the effective doses in our study are within the range used for human dosing, i.e., $0.5-2 \mathrm{mg}$ per dosing for haloperidol, which translates to approximately $0.01-0.03 \mathrm{mg} \mathrm{kg}^{-1}$ and 4-8 $\mathrm{mg}$ b.i.d. for risperidone, which translates to 0.03 $0.05 \mathrm{mg} \mathrm{kg}^{-1}$ per dose (for FDA dosing information about oral haloperidol and risperidone, see http://dailymed.nlm.nih. gov/dailymed/drugInfo.cfm?id=7211 and http://dailymed. nlm.nih.gov/dailymed/drugInfo.cfm?id=6159, respectively).

Effects of haloperidol and risperidone

on the $d$-amphetamine-induced behavioral activation in the $\mathrm{OF}$

Haloperidol tended to and risperidone did dose dependently antagonize the behavioral activation induced by $d$ amphetamine $\left(0.4 \mathrm{mg} \mathrm{kg}^{-1}\right)$. The high dose $\left(0.04 \mathrm{mg} \mathrm{kg}^{-1}\right)$ of both antipsychotics fully antagonized whereas the low dose $\left(0.01 \mathrm{mg} \mathrm{kg}^{-1}\right)$ only partially antagonized the effects of $d$-amphetamine for all parameters measured with the exception of mean duration of moving, which was not affected by amphetamine. Studies of rats have reported reversal of amphetamine $\left(0.63 \mathrm{mg} \mathrm{kg}{ }^{-1}\right)$-induced hyperlocomotion by haloperidol and risperidone, with an $\mathrm{ED}_{50}$ of $0.09 \mathrm{mg} \mathrm{kg}^{-1}$ s.c. haloperidol and $0.14 \mathrm{mg} \mathrm{kg}^{-1}$ s.c. risperidone (Bardin et al. 2007). Although no minimum effective doses are listed, the $0.04-\mathrm{mg} \mathrm{kg}^{-1}$ dose used as the high dose in the present study is at the low end of the $95 \%$ confidence intervals in the study by Bardin et al (0.04-0.17 $\mathrm{mg} \mathrm{kg}^{-1}$ and $0.03-0.56 \mathrm{mg} \mathrm{kg}^{-1}$ for haloperidol and risperidone, respectively). The $0.04-\mathrm{mg} \mathrm{kg}^{-1}$ dose is on the low end of this confidence interval, but the dose of $d$-amphetamine used to induce hyperlocomotion was also higher than in the present study. Taken together, these data indicate that the minimal effective dose for attenuation/ reversal of $d$-amphetamine-induced activity is similar in pigs and rats. Moreover, the $0.01-\mathrm{mg} \mathrm{kg}^{-1}$ dose of haloperidol, which was active in the present study, is in the range of doses used in non-human primates $\left(0.015 \mathrm{mg} \mathrm{kg}^{-1}\right.$ s.c. $)$ for reversal of $d$-amphetamine-induced behavior (Peacock and Gerlach 1999). This dose is ineffective in suppressing locomotion in rodents. This supports the closer pharmacological homology between minipigs and primates than between rodents and primates, further supporting the putative translational relevance of minipigs for pharmacological studies.

\section{Conclusions}

In conclusion, $d$-amphetamine at a dose of $0.4 \mathrm{mg} \mathrm{kg}{ }^{-1}$ body mass induced a specific pattern of locomotor activity 
in male Göttingen minipigs. This effect on locomotor activity in the OF was (dose dependently) attenuated by haloperidol and risperidone. In addition, both antipsychotics dose dependently reduced spontaneous locomotor activity in the OF.

The $d$-amphetamine-induced behavioral activation of minipigs may be a valuable animal model for testing the efficacy of novel putative antipsychotics and may be considered as an alternative to the use of non-human primates.

Acknowledgments We would like to thank Rita Hoving-Bolink and Lars Claassens for expert technical assistance.

Conflict of interest The study was partially sponsored by Johnson \& Johnson and was performed at "BioMedical Research" which is a contract research organization of Wageningen University and Research Center.

Open Access This article is distributed under the terms of the Creative Commons Attribution Noncommercial License which permits any noncommercial use, distribution, and reproduction in any medium, provided the original author(s) and source are credited.

\section{References}

Bardin L, Auclair A, Kleven MS, Prinssen EP, Koek W, NewmanTancredi A, Depoortere R (2007) Pharmacological profiles in rats of novel antipsychotics with combined dopamine D2/serotonin 5-HT1A activity: comparison with typical and atypical conventional antipsychotics. Behav Pharmacol 18:103-118

Björklund A, Dunnett SB (2007) Fifty years of dopamine research. Trends Neurosci 30:185-187

Chapret RL, Barron EL, Marrenfeltz JK, Dalton TK, Wolfe WW (1973) The miniature pig: a biomedical model for behavioral studies. Lab Anim Sci 23:711-715

Chen K, Baxter T, Muir WM, Groenen MA, Schook LB (2007) Genetic resources, genome mapping and evolutionary genomics of the pig (Sus scrofa). Int J Biol Sci 3:153-165

Cotton JW (1998) Analyzing within-subjects experiments. Lawrence Erlbaum Associates, Mahwah

de Groot J, Boersma W, van der Staay FJ, Niewold T, Stockhofe N, Koopmans SJ, van der Lende T, Schuurman T (2005) Development of domestic animal models for the study of the ontogeny of human disease. In: Hodgson D, Coe C (eds) Perinatal programming: early life determinants of adult health \& disease. Taylor \& Francis, London, pp 117-128

Elman I, Borsook D, Lukas SE (2006) Food intake and reward mechanisms in patients with schizophrenia: implications for metabolic disturbances and treatment with second-generation antipsychotic agents. Neuropsychopharmacology 31:2091-2120

Featherstone RE, Kapur S, Fletcher PJ (2007) The amphetamine-induced sensitized state as a model of schizophrenia. Prog Neuropsychopharmacol Biol Psychiatry 31:1556-1571

Geyer MA, Ellenbroek B (2003) Animal behavior models of the mechanisms underlying antipsychotic atypicality. Prog Neuropsychopharmacol Biol Psychiatry 27:1071-9
Grilly DM, Loveland A (2001) What is a "low dose" of d-amphetamine for inducing behavioral effects in laboratory rats? Psychopharmacology (Berl) 153:155-69

Haddad PM, Wieck A (2004) Antipsychotic-induced hyperprolactinaemia: mechanisms, clinical features and management. Drugs 64:2291-2314

Higgins GA (1998) From rodents to recovery-development of animal models of schizophrenia. CNS Drugs 9:59-68

Iversen SD, Iversen LL (2007) Dopamine: 50 years in perspective. Trends Neurosci 30:188-193

Jablensky A, Sartorius N, Ernberg G, Anker M, Korten A, Cooper JE, Day R, Bertelsen A (1992) Schizophrenia manifestations, incidence and course in different cultures. A World Health Organization ten-country study. Psychol Med 22:1-97

Jin H, Meyer JM, Jeste DV (2004) Atypical antipsychotics and glucose dysregulation: a systematic review. Schizophr Res $71: 195-212$

Kiang M, Daskalakis ZJ, Christensen BK, Remington G, Kapur S (2003) Actigraphic measurement of the effects of single-dose haloperidol and olanzapine on spontaneous motor activity in normal subjects. J Psychiatry Neurosci 28:293-9

Larsen MO, Rolin B (2004) Use of the Göttingen minipig as a model of diabetes, with special focus on type 1 diabetes research. ILAR J 45:303-313

Lind NM, Arnfred SM, Hemmingsen RP, Hansen AK, Jensen KH (2005a) Open field behaviour and reaction to novelty in Göttingen miniature pigs: effects of $d$-amphetamine and Haloperidol. Scan J Lab Animal Sc 32:103-112

Lind NM, Olsen AK, Moustgaard A, Jensen SB, Jakobsen S, Hansen AK, Arnfred SM, Hemmingsen RP, Gjedde A, Cumming P (2005b) Mapping the $d$-amphetamine-evoked dopamine release in the brain of the Göttingen minipig. Brain Res Bull 65:1-9

Lind NM, Moustgaard A, Jelsing J, Vajta G, Cumming P, Hansen AK (2007) The use of pigs in neuroscience: modeling brain disorders. Neurosci Biobehav Rev 31:728-751

Lunney JK (2007) Advances in swine biomedical model genomics. Int J Biol Sci 3:179-184

Noldus LPJJ, Spink AJ, Tegelenbosch RAJ (2001) EthoVision: a versatile video tracking system for automation of behavioral experiments. Behav Res Methods Instrum Comput 33:398414

Nordquist RE, Savignac H, Pauly-Evers M, Walker G, Knoflach F, Borroni E, Glaentzlin P, Bohrmann B, Messer J, Ozmen L, Albientz A, Spooren W (2008a) Characterization of behavioral response to amphetamine, tyrosine hydroxylase levels and dopamine receptor levels in neurokinin 3 receptor knockout mice. Behav Pharmacol 19:518-529

Nordquist RE, Vanderschuren LJ, Jonker AJ, Bergsma M, de Vries TJ, Pennartz CM, Voorn P (2008b) Expression of amphetamine sensitization is associated with recruitment of a reactive neuronal population in the nucleus accumbens core. Psychopharmacology (Berl) 198:113-26

Nunoya T, Shibuya K, Saitoh T, Yazawa H, Nakamura K, Yasuko Baba Y, Hirai T (2007) Use of miniature pig for biomedical research, with reference to toxicologic studies. Exp Toxicol Pathol 20:125-132

Peacock L, Gerlach J (1999) New and old antipsychotics verus clozapine in a monkey model: adverse effects and antiamphetamine effects. Psychopharmacology (Berl) 144:189-197

Peacock L, Hansen L, Mørkeberg F, Gerlach J (1999) Chronic dopamine D1, dopamine D2 and combined dopamine D1 and D2 antagonist treatment in Cebus apella monkeys: antiamphetamine effects and extrapyramidal side effects. Neuropsychopharmacology 20:35-43 
Schook LB (2007) The porcine genome initiative: implications for digestive physiology. Livestock Sci 108:6-12

Spink AJ, Tegelenbosch RAJ, Buma MOS, Noldus LPJJ (2001) The EthoVision video tracking system - a tool for behavioral phenotyping of transgenic mice. Physiol Behav 73:731-744

Svendsen O (2006) The minipig in toxicology. Exp Toxicol Pathol $57: 335-339$

Terlouw EMC, de Rosa G, Lawrence AB, Illius AW, Ladewig J (1992) Behavioural responses to $d$-amphetamine and apomorphine in pigs. Pharmacol Biochem Behav 43:329-340
Tumbleson ME (1986) Swine in biomedical research. Plenum, New York

Vodička P, Smetana K Jr, Dvořánková B, Emerick T, Xu YZ, Ourednik J, Ourednik V, Motlík J (2005) The miniature pig as an animal model in biomedical research. Ann N Y Acad Sci 1049:161-171

Weiner I, Gaisler I, Schiller D, Green A, Zuckerman L, Joel D (2000) Screening of antipsychotic drugs in animal models. Drug Dev Res 50:235-249

Winer BJ (1971) Statistical principles in experimental design, 2nd edn. McGraw-Hill, New York 